\title{
Aplicabilidade dos Jogos Eletrônicos no Ensino de Geografia: proposições para o jogo Red Dead Redemption 2
}

\author{
Applicability of Electronic Games in Geocience Education: propositions for the game \\ Red Dead Redemption 2
}

Aplicabilidad de los Juegos Electrónicos en la Educación en Geociencia: propuestas para el juego Red Dead Redemption 2

Leandro Baptista ${ }^{1}$

Diego Geovan dos Reis ${ }^{2}$

\begin{abstract}
RESUMO: Enquanto os videogames têm sido uma forma de entretenimento por décadas, só recentemente eles têm chamado a atenção da academia. Embora haja um número crescente de estudiosos que trabalham com videogames nas novas mídias e Gamestudies, a Geografia está apenas começando a se debruçar sobre os jogos e as práticas a eles associadas. Portanto, este trabalho tem como problema de pesquisa perceber de que forma o jogo Red Dead Redemption 2 contribui para o ensino desta ciência. Assim, seu objetivo foi investigar elementos geográficos do jogo como subsídios para o ensino de aspectos da Geografia física, para a alunos a partir do 9o ano. O artigo faz uso da metodologia criada por Ash (2009) para analisar a epistemologia dos Gamestudies através de uma abordagem geográfica, a qual propõe destacar as geografias nos videogames (em termos de representações), e então fazer uso do jogo como ferramenta pedagógica. Como resultado deste trabalho, foi realizado um levantamento de diversas imagens do jogo que permitem assimilar aspectos como relevo, formações rochosas e fósseis, entre outros, que podem ser incorporadas no planejamento de aulas que envolvam estas temáticas. A partir deste estudo espera-se ampliar a abordagem geográfica dos videogames e permitir a compreensão da interconexão dos jogos com o ensino.
\end{abstract}

PALAVRAS-CHAVE: Videogames. Geografia. Ensino.

ABSTRACT: While videogames have been a popular form of entertainment for decades, only recently they have caught attention of the academy. While there are a burgeoning number of video game scholars in the new media and Gamestudies, geography is just beginning to address the games and their associated practices. This work has a research problem to understand how the game Red Dead Redemption 2 contributes to the teaching of this science. Thus, its objective was to investigate geographic elements of the game as subsidies for teaching aspects of physical geography, for students from the 9th grade. This paper use of the methodology created by geographer James Ash (2009) to analyze Gamestudies epistemology through a geographical approach, which proposes to underline the

\footnotetext{
${ }^{1}$ Departamento de Turismo da Universidade Estadual de Ponta Grossa - PR. Campus Central - Bloco A - Sala 25, Praça Santos Andrade, no 01 - Centro. CEP 84010-919 - Ponta Grossa - PR. leandro.baptista@live.com.

2 Universidade Estadual do Centro-Oeste (UNICENTRO). R. Salvatore Renna, 875 - Santa Cruz, Guarapuava PR, 85015-430. diego.gdosreis@gmail.com.
} 
geographies in videogames (in terms of representations), and then make use of the game Red Dead Redemption 2 as a pedagogical tool for teaching some aspects of physical geography to 8th grade students onwards. As a result of this work a survey of several images of the game was carried out that allow the assimilation by representation of various aspects of Geography and Geology, such as relief and specific rock formations, which, once applied, may bring to light a systematic geographical approach. videogames in their various possibilities of analysis and will allow the understanding of the interconnection of games with the teaching of geography.

KEYWORDS: Videogames. Geosciences. Education.

RESUMEN: Mientras los videojuegos han sido una forma popular de práctica y entretenimento por décadas, solo ahora recientemiente están llamando la atención de la academia. Aunque haya numerosos de estudiosos que trabajan con videojuegos en los medios y Gamestudies, la geografía apenas está empezando a abordar sobre los juegos e sus prácticas que se associan a ellos. Este trabajo utiliza la metodología creada por el geógrafo James Ash (2009) para analizar la epistemología de los Gamestudies atraves del enfoque geográfico que propone subrayar las geografías en los videojuegos (con términos de representaciones), y con eso, utilizar el juego Red Dead Redemption 2 como herramienta pedagogica para enseñar algunos aspectos de la geografia física a los alumnos del $8^{\circ}$ grado en adelante. Como resultado de este trabajo se realizó un levantamiento de varias imagenes del juego que permite la comparación por representaciones de diversos aspectos de la geografia e de la geologia como el relievo y formaciones rocosas específicas que, una vez aplicada, puede sacar a la luz un sistemático enfoque geografico de los videojuegos con diversas posibilidades de analise y permitir la comprensión de la interconexión de los juegos, enseñando la geografia.

PALABRAS-CLAVE: Videojuego. Geociência. Enseñanza.

\section{INTRODUÇÃO}

Com a emergência de uma nova perspectiva denominada Geografia Cultural, constituída a partir da década de 1970, observou-se na ciência geográfica um amplo movimento de renovação epistemológica. Os geógrafos passaram então a se debruçar sobre novos temas e problemáticas de estudos, antes tidos como inadequados como, por exemplo, o estudo das representações. Esses estudos buscam compreender os "[...] instrumentos utilizados pelos seres humanos para apreender a realidade do meio ambiente e do meio social" (CLAVAL, 1997, p. 161) nos quais habitam. Alguns dos pesquisadores deste grupo de teóricos que aderiram a esta perspectiva dedicaram-se ao estudo dessas diversas formas de representações espaciais observadas em diversas mídias, como músicas e filmes. Há, não obstante, uma corrente midiática de considerável caráter representacional que apenas recentemente vem chamando a atenção da academia, os videogames.

O interesse acadêmico sobre os videogames iniciou-se por áreas como a Antropologia, Sociologia, Psicologia, Matemática e Pedagogia, dado o considerável teor pedagógico por eles proporcionado, o que acabou por culminar nos chamados Gamestudies, em tradução livre - estudos de jogos (ASH, 2009). O foco nas perspectivas contextuais orientadas dos jogos e o interesse nas conexões entre os jogos e a "vida real" apontam para um significante 
papel na constituição dos Gamestudies como campo de pesquisa. Estas perspectivas, apontadas por Lowood (2006), têm contribuído para ampliar a percepção dos jogos como relevantes objetos de estudos e legítimo instrumento para o ensino.

Este trabalho pauta-se na primeira abordagem identificada por Ash, ou seja, a Geografia nos videogames, mais enfaticamente no conteúdo educacional passível de ser produzido através dos modelos geográficos por eles representados. Para tal, tem como problema de pesquisa perceber de que forma o jogo Red Dead Redemption 2, ou RDR2, contribui para o ensino desta ciência. Desta forma utiliza-se como objeto de estudo o jogo Red Dead Redemption 2, produzido pela Rockstar Inc. O recorte desse estudo é o ensino de Geografia aos alunos a partir do 9o ano. Estipula-se assim como objetivo principal investigar os elementos geográficos do jogo como subsídios para o ensino de aspectos da Geografia física, para explicar e ensinar aspectos relacionados ao ensino das geociências. Tal objetivo será caracterizado por outras especificidades, sendo elas: 1) Analisar e estudar o jogo RDR2 para identificar potencialidades de usos no ensino de Geografia. 2) Elaborar propostas didáticas que possam utilizar as potencialidades identificadas no objetivo anterior, com intuito de ensinar aspectos da formação do espaço geográfico; interpretação de mapas e recursos cartográficos; noções de geomorfologia e outros aspectos da geografia física.

Esta pesquisa surgiu através da percepção de que os jogos fazem parte do cotidiano dos alunos, no entanto, sem serem aproveitados como um mecanismo de educação extraclasse. Ora, se é sabido que a Geografia está em todos os lugares, é igualmente factual que os educadores utilizem todo o potencial para fazer com que os discentes consigam perceber e compreender os conceitos também de forma lúdica.

A metodologia é constituída em dois eixos, sendo o primeiro a revisão bibliográfica sobre a temática, ou seja, a Geografia nos Gamestudies e formas inovadoras de se utilizar da tecnologia para ensinar. O segundo eixo consta da elaboração das potencialidades pedagógicas por meio de imagens criteriosamente selecionadas para explicar os conteúdos específicos.

O método utilizado é o criado pelo geógrafo britânico James Ash o qual analisa os jogos sob um prisma que vai além do adotado pelos Gamestudies, pautado unicamente na ludologia e narratologia, seu método estuda os jogos sob uma perspectiva geográfica que compreende três etapas distintas, a Geografia dos videogames, os videogames como prática geográfica e a Geografia nos videogames, em termos de representação, na qual este trabalho está concentrado.

Esta pesquisa consiste de uma pesquisa qualitativa de caráter basal, bibliográfico e documental, que, segundo Lüdke (1986), tem como finalidade obter dados voltados à compreensão de determinados fenômenos sem considerar o caráter numérico da questão, o que possibilitará a criação de uma determinada tese que poderá ser testada. Os passos 
procedimentais foram, nessa ordem, a leitura bibliográfica sobre os Gamestudies e sua relação com a Geografia, bem como consulta documental sobre o jogo utilizado. Em um segundo momento os autores realizaram a prática do jogo com intuito de buscar imagens específicas que pudessem ser utilizadas como referencial para o alcance do objetivo central do texto. Por fim, sugere-se a continuação dessa pesquisa a partir da aplicação prática desse material e em seguida apontar caminhos futuros.

\section{O ENSINO DA GEOGRAFIA}

Atualmente o ensino possibilita a incorporação de novas didáticas, valendo-se de recursos que não foram essencialmente destinados a este fim. Castells (1999) há mais de duas décadas alertava para a formação de uma sociedade em rede, para explicar o intenso e expressivo uso das tecnologias da informação. Entende-se que os recursos tecnológicos podem auxiliar na construção do conhecimento, tendo o professor em sua prática docente um sistema inovador e dinâmico que trespasse a sala de aula a partir da mediação entre as questões geográficas e cotidianas, como algo que proporcione o entendimento e reflexão do contexto diário do aluno (PINTO; CARNEIRO, 2019).

Esta percepção corrobora com a crítica de Lacoste (1988) ao alertar que a Geografia era uma disciplina cansativa e entediante, estudada, muitas vezes, somente através do livro didático. A complexidade da geografia exige que esta fundamente-se na explicação e interpretação de fatos, representações e materialidades. Desta maneira, os preceitos e conceitos geográficos devem se fazer presentes no cotidiano dos alunos.

Sene (2010) e Kaercher (2015) destacam que o professor de geografia deve incentivar o aluno a descobrir novos olhares que estão à sua volta, relacionar as informações conceituais ao mundo cotidiano de nossos alunos e fazê-los entender o espaço geográfico modificado e alterado pelas ações humanas. Hardwick (2004, p. 30) já chamava atenção sobre a relação entre alunos e tecnologias, quando argumentou que "[...] os educandos são fascinados pelos computadores, pela imagem no lugar da escrita, por jogos, então é interessante incorporar tudo isso na estratégia de ensino".

Essas estratégias são importantes no âmbito das práticas geopedagógicas a partir da transposição metodológica e didática no decorrer do planejamento das aulas, a partir de uma relação dialética docente/discente do processo de ensino-aprendizagem (PINTO; CARNEIRO, 2019).

Portanto, este artigo visa avançar também no debate de Pinto e Carneiro (2019), para contribuir na construção de um conjunto de ideias e de como o ensino de geografia pode ser articulado com práticas não formais de aprendizagem. 


\section{A GEOGRAFIA E OS VIDEOGAMES}

Os videogames constituem um fenômeno da cultura tecnológica atual. Apesar disso, eles permanecem sub-representados nos estudos da Geografia. Enquanto geógrafos culturais têm frequentemente atentado para outras mídias, em particular, filmes, música e literatura, os videogames têm supreendentemente recebido pouca atenção. Os videogames têm ocupado a consciência popular por pelo menos 30 anos. Eles podem ser jogados em uma variedade de mídias desde computadores de casa, gabinetes de arcade, consoles de videogames a smartphones.

No entanto, a ciência geográfica estava fora desse escopo epistemológico e só apenas no início do século XXI começou a investigar os Gamestudies. No Brasil, porém, são escassas as obras que abordam a temática, como as dos geógrafos Alvarenga (2007) e Drummond (2014). É pertinente observar que os estudos geográficos sobre os videogames recaem principalmente sobre as formas de representação, através do espaço virtual criado pelas imagens e seus signos e do desenvolvimento da trama, através dos diálogos e enredos. $O$ estudo das representações, contudo, não compreende a única forma com a qual a Geografia, seja Humana, Crítica e até mesmo Física, pode abordar os jogos, deixando um grande espaço aberto para a prática pedagógico-geográfica, ou seja, o ensino da Geografia a partir dos jogos.

James Ash, geógrafo e professor do departamento de Geografia da Universidade de Newcastle, Inglaterra, é um dos pioneiros a abordar os Gamestudies sob uma perspectiva geográfica. Para Ash (2009) a Geografia tem abordado os videogames unicamente em seu aspecto representacional, ou seja, a forma como os jogos representam o espaço geográfico físico e político-cultural. No entanto, aponta que há outras formas da Geografia se debruçar sobre os estudos dos videogames, tendo assim criado uma metodologia de análise geográfica dividida em três categorias: 1) A Geografia nos videogames (em termos educacionais e de representações político-culturais dentro dos jogos); 2) A Geografia dos videogames (em termos de produção e consumo dos jogos); e 3) Os videogames como prática geográfica cultural (em termos de práticas tecnológicas através das quais os jogos e jogadores são produzidos). Cada uma dessas categorias de análise permite estudos aprofundados sobre diferentes aspectos da Geografia envolta nos videogames.

Juntamente a uma variedade de recursos técnicos para acessar os videogames, existe uma gama de gêneros de jogos - incluindo jogos de corrida, jogos de Tiro em Primeira Pessoa e jogos de RPG (Role Playing Games), sendo que cada um deles faz uso de diferentes estilos gráficos, convenções espaciais e assim por diante. Assim sendo, o termo "videogame" referese menos a um único e identificável objeto e mais a uma infinidade de tecnologias, gêneros e materialidades. 
Os trabalhos especializados, referidos como Gamestudies, estão frequentemente preocupados com o desafio de definir os videogames. Pesquisadores vêm tentando "[...] desenvolver uma ontologia, tipologia e classificação formal” (BOGOST, 2006, p. 12, tradução dos autores), a qual permitiria demonstrar as maneiras pelas quais os videogames são diferentes de, ou similar a, outras mídias como filmes. Em contraste a estes, os videogames são constituídos por uma diversidade deveras maior de recursos tecnológicos que permitem a interação do sujeito com o espaço criado pelo jogo.

Prover uma absoluta e universal definição dos videogames é tarefa quimérica. Por exemplo, alguns tipos de jogos seguem o que Jesper Juul (2002) descreve como uma progressão estrutural na qual os criadores controlam a sequência de desafios e eventos prédeterminados que os usuários experienciam como história do jogo. Jogos de Aventura e RPGs, tais quais Final Fantasy XII, frequentemente seguem esse tipo de estrutura, assim como os Modo História dos jogos de tiro em primeira pessoa como Call of Duty 4.

Juul (2002) também identifica outro tipo de estrutura de jogo: imersão. Esses tipos de jogos oferecem um pequeno número de regras, das quais uma grande variedade de situações dos jogos e eventos ocorrem. Essa estrutura é encontrada em todos os jogos de estratégia incluindo Turn-basd Strategy games (TBS) como Civilisation, e Real-Time Strategy games (RTS) como Dune II - e também em modos multiplayer dos jogos FPS como Call of Duty 4 (ASH, 2009). Juul (2002) explica que os Massively Multiplayer Online Role-Playing Games (MMORPGs), como Everquest, combinam elementos de progressão e imersão, tal é que eles oferecem uma experiência de mundo aberto para um grande número de jogadores (uma estrutura de imersão), mas com questões construídas (estrutura de progressão).

As tentativas de produzir uma tipologia dos videogames têm frequentemente focado ou na maneira como os diferentes videogames combinam narrativa (perspectiva narratológica) ou nas regras e outros aspectos da gameplay nos videogames (perspectiva ludológica). A ação de jogar produz a narrativa, a qual é gerada ao redor de improvisação colaborativa, parcialmente gerada pelos autores dos códigos e parcialmente desencadeada pelas ações que o jogador toma no mundo mecânico. Essa forma de narrativa é diferente da televisão, por exemplo, porque as formas nas quais a narrativa se desenrola é moldada pela contingência das ações dos jogadores no mundo do jogo.

Jesper Juul (2002) argumenta que os videogames são compostos de regras reais e mundos ficcionais, e explica que as interações entre os dois são uma de suas mais importantes características. Para ele, é óbvio que as regras de um jogo influenciarão a forma como ele é jogado, mas ele argumenta que o valor da perspectiva ludológica no estudo dos videogames recai na explicação exata de como isso acontece. O autor, além do mais, argumenta que as seguintes questões deveriam ser integrais aos estudos dos videogames: "[...] o que é preciso para algo ser um videogame, e quando um videogame é agradável? 
Como funcionam as regras, e como elas proporcionam prazer para os jogadores? Como e por que o jogador imagina o mundo do jogo?" (JUUL, 2002, p. 8, tradução nossa). Os debates envolvendo narratologia e ludologia são baseados em partes em uma falsa dicotomia. Quando estão jogando, muitos usuários experienciam o jogo tanto como uma história com uma narrativa, quanto como um complexo sistema de representação de papéis. Com isso em mente, o termo "videogame" é mais usualmente concebido como um tropo discursivo, ao invés de uma definição precisa que pode agir como um separador sobre o qual cada jogo em si pode ser alocado. Concentrando-se no que os videogames são - tentando desenvolver um conjunto formal de definição e tipologia dos videogames - pesquisadores dos jogos frequentemente ignoram o porquê as pessoas na verdade jogam videogames. Eles arriscam perder a experiência de realmente jogar videogames e as práticas empregadas pelos jogadores individuais.

Há poucos estudos sobre como os jogos em si são jogados. Videogames envolvem habilidades com sofisticados softwares, geralmente em complexos ambientes virtuais. Há menos documentação e investigação das complexidades da hábil jogabilidade - ou seja, o que realmente atrai jogadores (REEVES, 2009, p. 206, tradução nossa).

As práticas e as experiências dos jogadores são frequentemente esquecidas quando os pesquisadores se concentram nas qualidades representacionais das imagens dos jogos ou na identidade dos usuários dentro de comunidades de jogadores. Os Gamestudies têm até agora apenas tentado tipificar os videogames e sua prática. É preciso assim explorar as formas pelas quais é possível à Geografia estudar os videogames (em termos de representação e política dentro dos videogames) e a Geografia dos videogames (em termos de produção e consumo de videogames). Tendo isso compreendido, pode-se pensar sobre as formas nas quais jogar videogame pode ser entendido como uma prática geográfica.

Muito da literatura sobre videogames na Geografia têm se estruturado na forma com a qual os jogos representam as pessoas, lugares e conceitos. Por exemplo, alguns geógrafos têm explorado as formas nas quais a natureza é representada nos jogos (LONGAN, 2008) e também as formas nas quais a engine gráfica dos jogos pode ser utilizada para simular paisagens específicas (ASH, 2009). No entanto, os estudos que investigam a Geografia nos videogames não tentam simplesmente descrever as formas nas quais grupos específicos ou paisagens são representadas nos jogos, eles geralmente incorporam um elemento de julgamento sobre as consequências de retratar pessoas e lugares de formas particulares. Como Michael Longan (2008, p. 23, tradução nossa) explica: “[...] os videogames não simplesmente incorporam as representações da paisagem, eles são por si mesmos uma forma de representação paisagística que comunica ideia sobre como o mundo é e como deveria ser". 
Outra conotação encontrada pelos geógrafos têm sido a preocupação com a sexualidade embutida nas representações nos videogames. Um aspecto particular desse tipo de trabalho tem sido a representação de gênero em vários jogos diferentes. Por exemplo, alguns pesquisadores exploraram a tipificação de gênero, muitas vezes hipersexualizada, dos personagens dos jogos (LEONARD, 2009). Similarmente, outros têm se interessado nas formas pelas quais os jogos reforçam a heteronormalidade através de um retrato de outras sexualidades ou, de fato, a invisibilidade de personagens gays, lésbicas, bi-sexuais e transgêneros em muitos jogos (SHAW, 2009). Nesse sentido, os videogames podem legitimar esses estereótipos através da produção de relações intertextuais entre eles mesmos e outras mídias.

Em outros casos, alguns pesquisadores exploraram as paisagens raciais dentro dos jogos e examinaram as formas nas quais eles reforçam alguns estereótipos de raça, como Higgin (2008, p. 7-8):

[...] preocupante é que os mundos dos videogames continuam impregnados com representações racistas, incluindo o quase universal retrato de protagonistas brancos nos jogos. Esse privilégio do usuário normativo branco ainda é amplamente prevalente em novas formas de mídia e no ciberespaço, criando topografias altamente raciais e frequentemente racistas.

Em um contexto político pós ataque terrorista de 11 de setembro de 2001 ao World Trade Center em Nova York (EUA) muitos estudos estão particularmente preocupados com a representação orientalista dos árabes nos videogames, por exemplo, Witheford e Peuter, (2009), que argumentam que o retrato dos inimigos árabes nos videogames, como em Call of Duty 4: Modern Warfare, problematicamente reforça ideias pré-existentes de alteridade e, assim, produzem potenciais paisagens racistas.

Note-se que os videogames nunca são politicamente neutros. Marcus Power (2007) tem argumentado que jogos com temática militar trabalham para moldar o entendimento popular de geopolítica e contribuem para o que ele chama de militarização da vida diária. Como ele explica: "[...] jogos digitais de guerra colocam uma face amigável e hospitaleira nos militares, fabricando o consenso e a cumplicidade entre os consumidores a respeito de programas militares, missões e armamentos" (POWER, 2007, p. 278, tradução nossa). Através do exemplo do America's Army - o jogo oficial do exército americano - Power explica que os videogames trabalham para legitimar e produzir consenso para a política governamental, a qual é baseada em uma cultura de guerra perpétua.

A geografia dos videogames pode ser situada dentro de mais amplas trajetórias de geografias virtuais do ciberespaço e dos territórios informacionais (DODGE, 2009). Encontram-se vários estudos que têm investigado como as identidades culturais e redes sociais são formadas nos mundos sintéticos e virtuais dos jogos online. Por exemplo, os 
pesquisadores têm explorado o desenvolvimento de comunidades e espaços sociais em uma variedade de jogos online e mundos virtuais, como Second Life (BOELLSTORFF, 2010), entre outros. Os ambientes imersivos e sintéticos nos jogos MMORPG podem ter um efeito extremamente positivo em termos de construir comunidades e culturas únicas, mas há também consequências negativas, que podem incluir cyberbullying e sérios vícios. Culturas assim podem também ser construídas em jogos que não são jogados online.

No entanto, enquanto os videogames podem ser apontados como construtores de mundos "virtuais", eles são sempre, inevitavelmente, jogados no mundo "real". Como formas anteriores de TDIC - Tecnologias Digitais da Informação e Comunicação, os videogames têm efeitos muito reais na organização dos espaços sociais e culturais nos quais eles são jogados (SIVERSTONE; HIRCH, 1992). Como exemplo pode-se observar o mais recente jogo da Nintendo, Pokémon Go, um jogo de realidade aumentada que interliga o espaço dito virtual ao espaço geográfico real, criando territórios informacionais nos quais os jogadores se encontram fisicamente, para participar de atividades desenvolvidas em um espaço virtual.

Distinguir esses territórios dentro desses espaços é tarefa cada vez mais complexa em uma sociedade inter-conectada entre esses dois paralelos. Entender a Geografia cultural dos jogos, dessa forma, é importante porque evidencia que não todos que jogam videogames irão experienciá-los da mesma forma. Ao observar as múltiplas maneiras pelas quais os videogames são interpretados e usados em diferentes tempos e espaços, é possível considerar as maneiras que o público ativamente interpreta e se apropria de vários jogos de forma única, ao invés de apenas recebê-los passivamente, como ocorre com filmes.

O "espaço virtual" é frequentemente oposto ao "espaço real", da vida cotidiana. De fato, a explicação é de alguma forma teleológica, ela artificialmente cria um domínio chamado virtual, o qual é entendido como separado dos ambientes verdadeiros ou reais. Mundos "virtuais" não se colocam ao lado de mundos "reais", eles são por si mesmos mundos reais, os quais são trazidos à vida através de práticas materiais e tecnológicas.

O espaço vivido dos jogos vai além do ciberespaço, pois ele não existe apenas online e interage de várias formas com o jogador, trata-se de um aspecto subjetivo da espacialidade experienciada. Adotando o termo da fenomenologia, esse mundo "virtual" constitui o "mundo vivido" (Lebenswelt) e o jogador o próprio "ser-no-mundo", aproximando assim o conceito geográfico de lugar ao mundo do jogo. É interessante notar que Tuan (1983) afirma que o conceito de espaço está orientado e estruturado pela intencionalidade do ser. Ora, para muitos jogadores a realidade dos jogos chega a substituir sua realidade espaço-temporal, por exemplo em jogos simuladores de segundas vidas, como Second Life. Relph (1976) identifica seis tipos de espaço: o pragmático, o perceptivo, o existencial ou vivido, o do planejamento, o cognitivo e o abstrato. Destarte, o espaço "virtual" dos jogos não é necessariamente virtual, 
pois pode ser alocado em mais de uma dessas definições. Ele não apenas representa o espaço, ele constitui um espaço independente que se interconecta com o espaço geográfico.

De modo similar, James Ash (2009) tem argumentado que as imagens dos videogames produzem uma forma de espaço tanto existencial quanto ecológica que resultam em uma experiência de mundo real para seus usuários. O sentido de mundo aqui não é o de uma coisa estável e neutra a qual preexiste às interações dos usuários com ela. É, antes de tudo, o sentido de um mundo processual que ativamente emerge das práticas dos usuários. Esse é o sentido de mundo em atualidade, no que veio a ser chamado de Teorias não Representacionais na Geografia Cultural.

Observar as formas como os usuários interagem com as regras dos jogos e aos recursos tecnológicos dos sistemas individuais dos videogames permite aos geógrafos desvendar algumas das maneiras pelas quais o espaço e o tempo são reprojetados como resultados de mudanças contínuas na cultura visual. Ash (2009) ainda argumenta que a habilidade dos jogadores para sentir o espaço e o tempo é uma função de seu campo fenomênico. Ele explica que, ao criar jogos e manipular suas regras, os criadores são capazes de indiretamente moldar o fenômeno observado por aqueles que usam seus jogos. Como resultado, as práticas de jogar podem produzir diferentes formas de concepções espaçotemporalmente orientadas.

Anteriormente neste texto, foi discutido o argumento de Marcus Power (2007) sobre as formas pelas quais jogos com temáticas militares moldam o entendimento popular de geopolítica e contribuem para o processo de militarização da vida cotidiana. Uma abordagem microetnográfica pode permitir aos pesquisadores estudar as assembleias tecno-culturais implicadas na prática de jogar videogames, pelas quais, por exemplo, jogos de temáticas militares são capazes de produzir consenso para políticas estatais entre muitos jogadores nos EUA. Traçar a experiência corpórea de disparar armas de fogo em jogos militares comuns (como Call of Duty: Modern Warfare 2) pode ajudar a entender as práticas geográficas de jogar videogame como parte de um processo o qual medeia e produz entendimentos populares de geopolítica e atitudes em relação aos conflitos do mundo real.

As complexas inter-relações entre essas três vertentes: a Geografia nos videogames, a Geografia dos videogames e os videogames como prática geográfica cultural são importantes à medida que elas apontam para formas pelas quais as experiências particulares de jogar videogame são filtradas e emergem através de uma variedade de processos culturais, espaciais e políticos que podem ser perdidos se utilizada apenas uma única abordagem. Atentar-se para os aspectos tecno-culturais do ato de jogar videogames como prática geográfica é útil porque oferece insights sobre como os videogames vêm a ter efeitos particulares no mundo. Ao observar os jogos como uma prática totalmente corpórea e material, os estudiosos podem ainda iluminar a Geografia nos e dos videogames. 
Há uma necessidade de desenvolver futuras e detalhadas investigações geográficas sobre a materialidade das diferentes interfaces de dispositivos que permitem aos usuários se envolver com plataformas de videogames, seus jogos e ambientes específicos. Uma delas é investigar como os jogos e os mundos por eles representados podem ser utilizados como ferramentas pedagógicas para o ensino de alguns conceitos da Geografia, e é a isso que se propõe este trabalho, especificamente com o jogo Red Dead Redemption 2.

\section{RED DEAD REDEMPTION 2 E O ENSINO DA GEOGRAFIA}

Red Dead Redemption 2 foi ambientalizado nos Estados Unidos de 1899, período que caracteriza o declínio do chamado "Velho Oeste" americano, pois a partir de então todo o território dos EUA passa a ser unificado e conhecido. A trama do jogo não acontece em um estado específico, sendo que os nomes dos lugares existentes no jogo são fictícios. No entanto, todos foram criados como representações de espaços reais, sendo assim, alguns estados e marcos de referência são claramente reconhecidos em sua representação virtual. Podemos citar como exemplo as Montanhas Rochosas, no caso do jogo mais especificamente a parte que corta o estado do Colorado. Os pântanos de Nova Orleans no estado de Louisiana são facilmente identificados nos arredores da cidade fictícia de Saint Denis. É impossível também não reconhecer a representação do Grand Canyon, no estado do Arizona, que no jogo fica no estado fictício de New Austin. Esses são apenas alguns exemplos de lugares reais que ganham suas versões virtuais em RDR2.

Ressalte-se aqui que os pontos referenciais retirados do jogo podem ser utilizados para qualquer disciplina das geociências, pois o que se enfatiza aqui é a metodologia em si, ou seja, a possibilidade de aliar o ensino de Geografia por meio do videogame, uma nova ferramenta pedagógica pautada epistemologicamente pelos gamestudies.

Muitos aspectos e referenciais foram selecionados, no entanto devido às limitações textuais serão apresentadas algumas delas apenas como aporte descritivo das possibilidades de uso do jogo como ferramenta de ensino de Geografia. Para melhor organizar e facilitar a compreensão do leitor, as imagens foram separadas em 5 categorias gerais, que são: cartografia; relevo e solos; geoformas; paleoformas e rochas em geral. Tendo isso especificado, nos próximos parágrafos serão expostos alguns exemplos, visando subsidiar o alcance do objetivo central deste estudo, ao investigar elementos geográficos do jogo como subsídios para o ensino de aspectos da Geografia física.

Cartografia: O mapa é item fundamental no jogo, sem ele jogar é deveras difícil dado a gigantesca dimensão do mundo de RDR2. O jogo traz um mapa bastante dinâmico, o jogador pode movimentá-lo, pode marcar pontos de interesse para seguir, além de ao longo do jogo encontrar diversos itens espalhados pelo mundo os quais exigem que o jogador siga o mapa 
para encontra-los. A Figura 1 apresenta o mapa do jogo, tendo à sua esquerda a exibição de uma parte do mapa de maneira geral, sendo possível, através deste, ensinar as noções cardeais, norte, sul, leste e oeste, que são identificadas no mapa. À direita, pode-se observar as curvas de nível, o que possibilita ensinar as diferenças de altitude no relevo, isto pode ser observado ao se fechar o mapa e voltar ao jogo. O mapa é também temático, ou seja, apresenta pontos de interesse, como localização de animais, itens etc, o que pode ser bastante útil aos alunos na elaboração de um mapa turístico, por exemplo.

Figura 1 - Mapa geral (à esquerda) e curvas de nível (à direita)

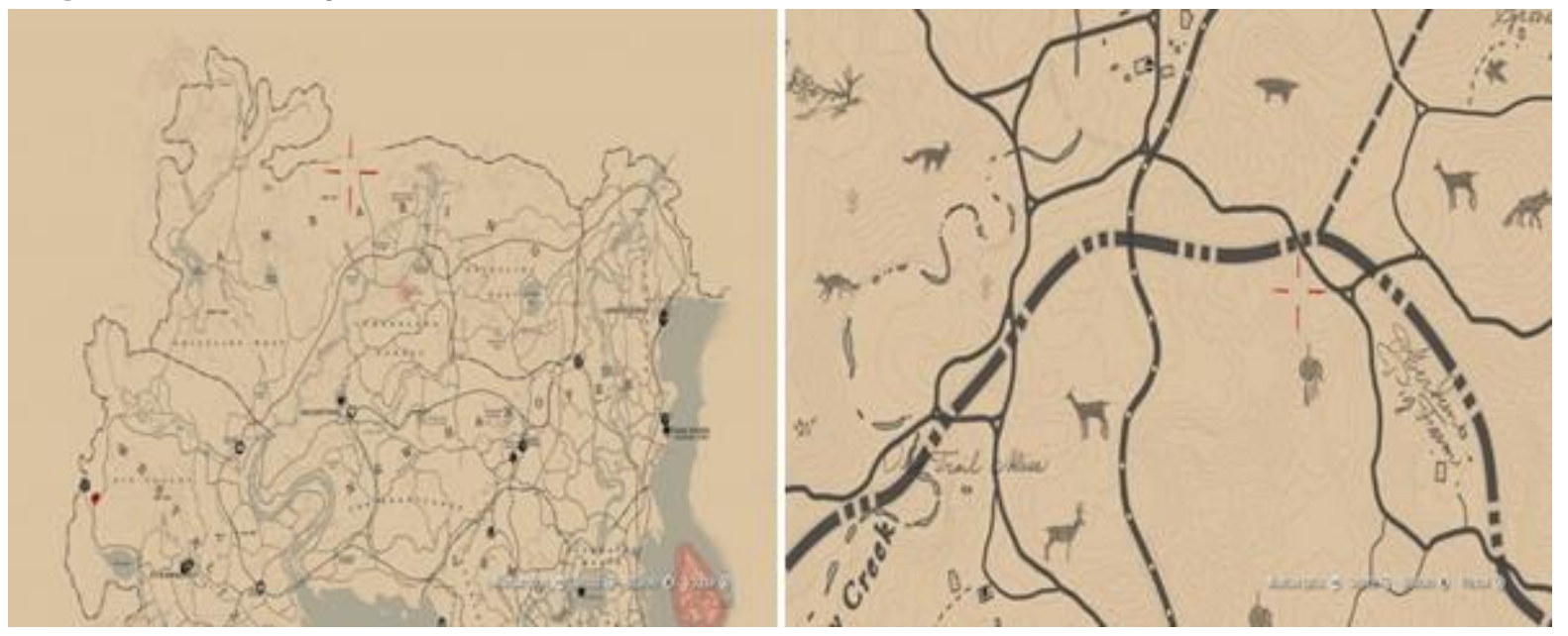

Fonte: Acervo particular dos autores, 2020 - Red Dead Redemption 2.

Relevo e solo: As características do relevo e do solo são marcantes em RDR2. É possível explicar diversas formas do relevo ao jogar. Além disso, algumas características específicas do solo podem ser identificadas e explicadas, como, por exemplo, a erosão. Foram separadas aqui algumas entre diversas possibilidades. Primeiramente serão apresentadas todas as imagens para então comentar sobre elas.

Na Figura 2 é possível observar a representação de dobras Anticlinais, Antiforma e Sinforma Sinclinais, o que permite o ensino das características dessas formas. Por sua vez, a Figura 3 representa um gnaisse intemperizado pela água acumulada nas diaclases e submetidas ao processo de congelamento, causando a desintegração na rocha e um gêiser, uma nascente termal que entra em erupção periódica, lançando água e vapor de água e junto a ele um depósito de geiserita. O gêiser visto no jogo representa os que estão em atividade dentro do Parque Nacional Yellowstone.

$\mathrm{Na}$ Figura 4 é representada uma pequena vila localizada em fundo de vale (em sua esquerda), permitindo a explicação e demonstração do que venha a ser essa característica do relevo e, à direita, pode-se exemplificar um processo erosivo fluvial, no caso do jogo é um processo causado pelo rio Bravo ao cortar o estado de New Austin e dar forma à paisagem. 
Essa é uma representação do rio Colorado que, ao atravessar o estado do Arizona, deu forma ao Grand Canyon.

Figura 2 - Dobra Anticlinal (à esquerda) e dobras Antiforma e Sinforma Sinclinal (à direita)
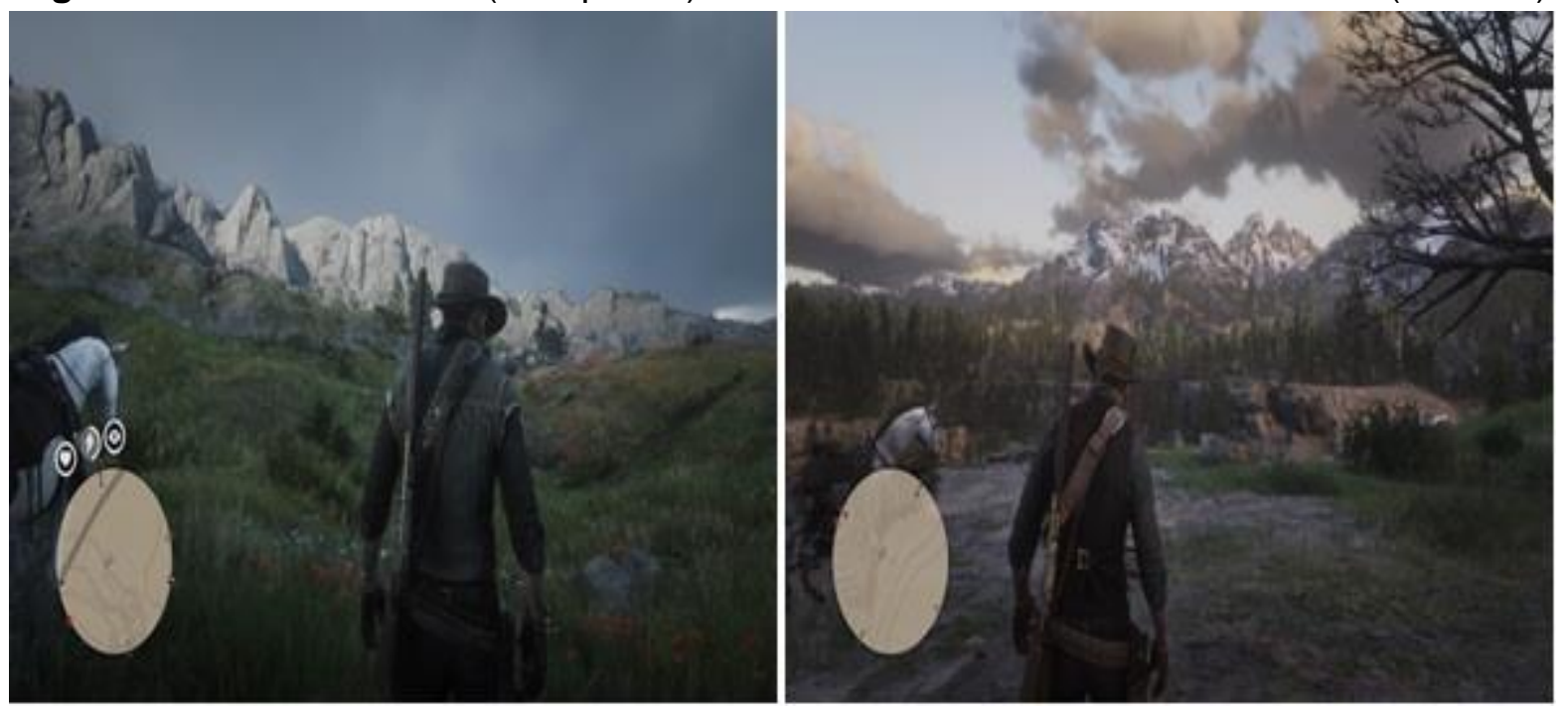

Fonte: Acervo particular dos autores, 2020 - Red Dead Redemption 2.

Figura 3 - Gnaisse, intemperismo por congelamento (à esquerda) e gêiser (à direita)
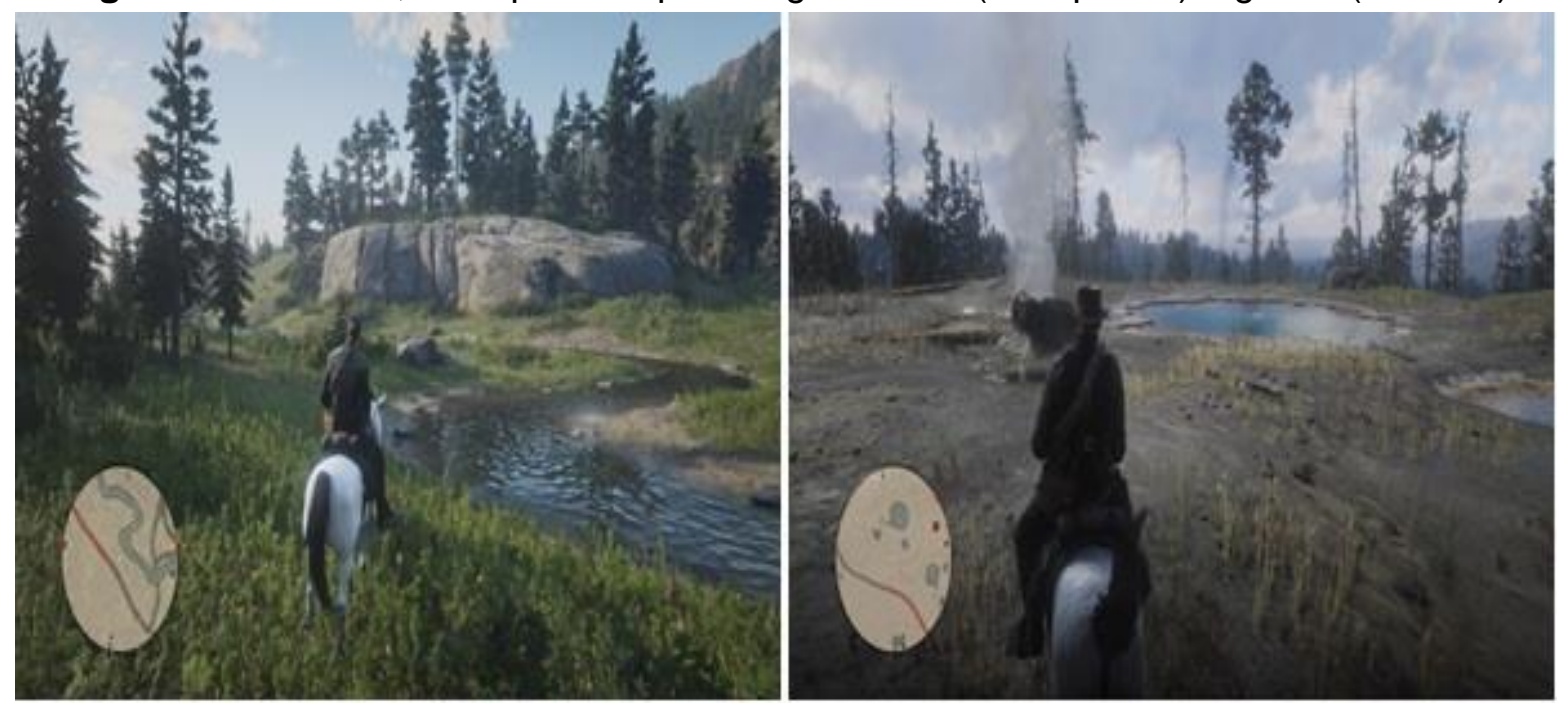

Fonte: Acervo particular dos autores, 2020 - Red Dead Redemption 2.

Através da Figura 5, à esquerda, é representado o mesmo local do mapa, porém observada de dentro do cânion. Nela pode-se observar as linhas de sedimentos nas paredes, características de rochas sedimentares. A partir dessas imagens se faz plausível ensinar tanto o processo erosivo quanto a explicação do tipo específico de rocha. Em relação à imagem na direita, é destacado um exemplo de erosão eólica corrasiva em relevo ruiniforme, semelhante ao processo que, em conjunto com o intemperismo, dá feição às geoformas do Parque Estadual de Vila Velha, em Ponta Grossa - PR. Ao jogar, é possível percorrer o entorno e observar as formas que caracterizam este relevo. 
Figura 4 - Vila em fundo de vale (à esquerda) e erosão fluvial (à direita)

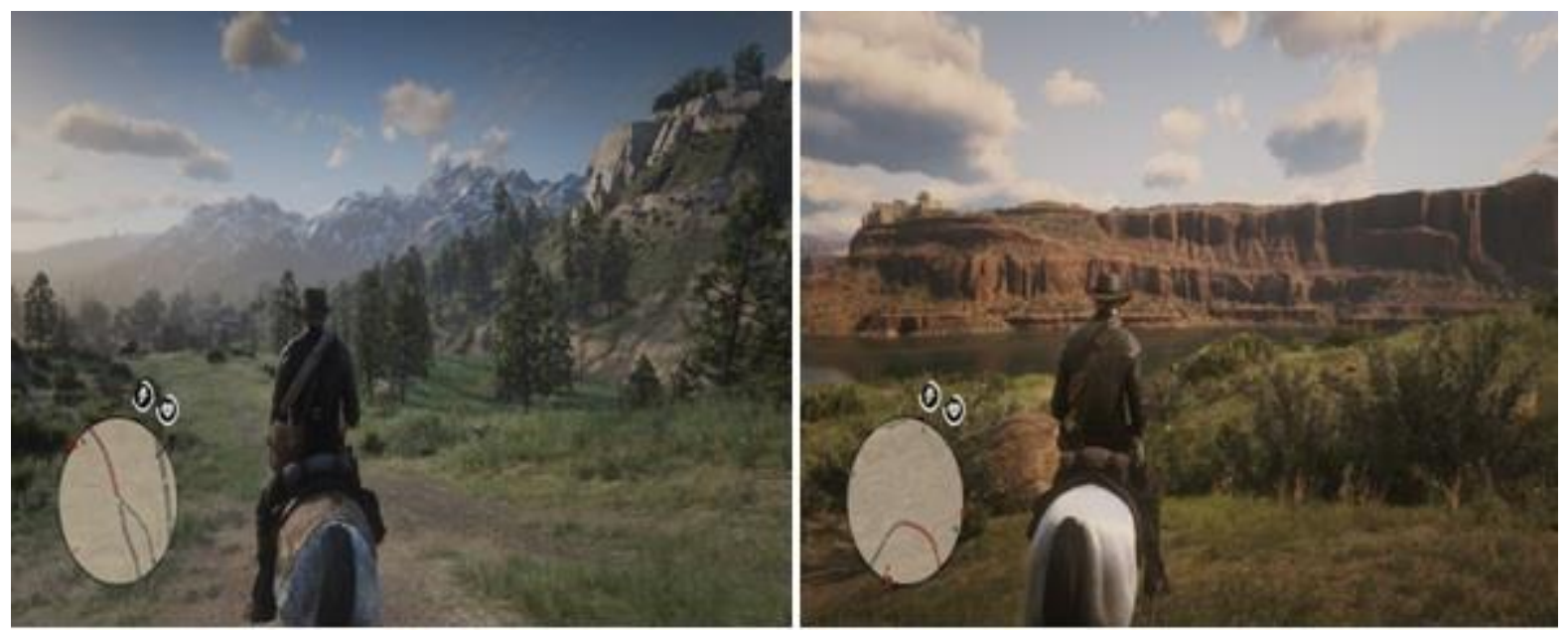

Fonte: Acervo particular dos autores, 2020 - Red Dead Redemption 2.

Figura 5 - Erosão fluvial em rocha sedimentar (à esquerda) e erosão eólica (à direita)
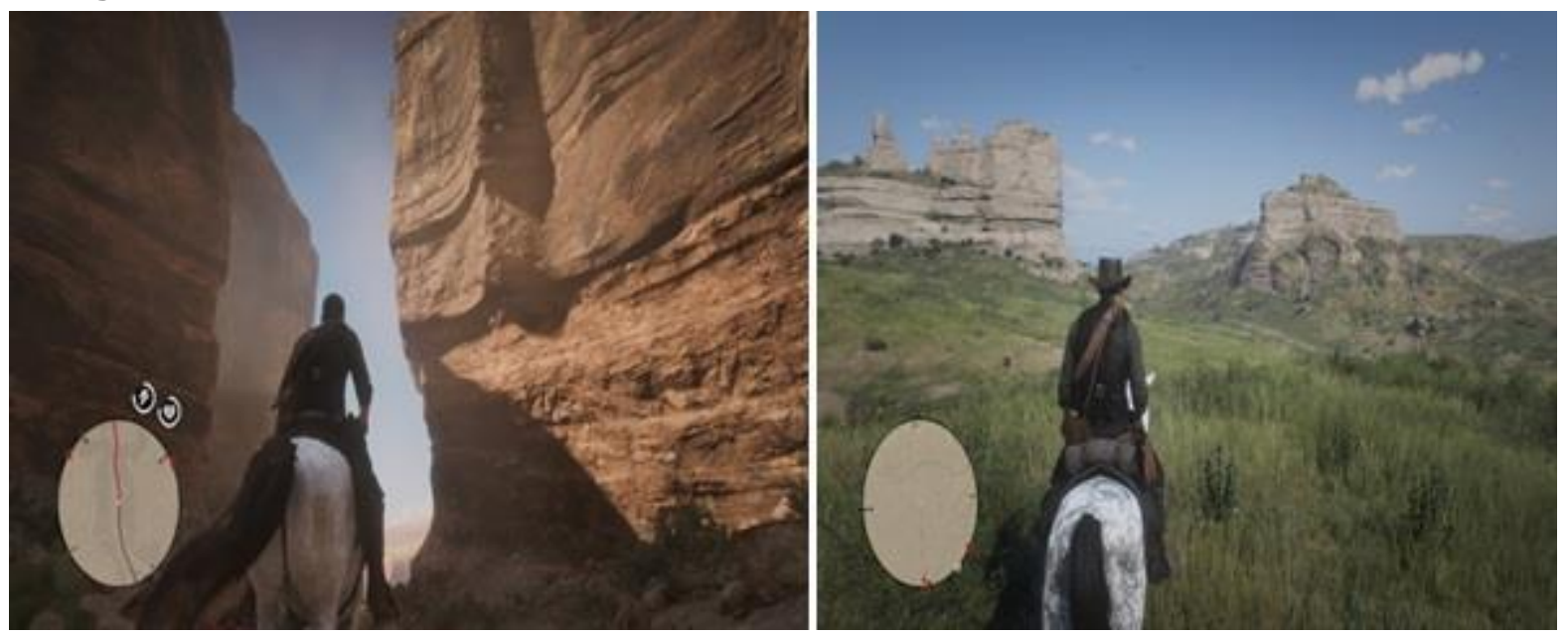

Fonte: Acervo particular dos autores, 2020 - Red Dead Redemption 2.

A Figura 6 apresenta uma paisagem que passa pelo processo de erosão antrópica, causada pela ação do homem, nesse caso específico o corte do solo para instalação da ferrovia (à esquerda). Por fim, a partir da representação à direita da mesma imagem observase uma planície de inundação, que pode ser mais bem observada ao jogar.

Cabe ressaltar que é possível retirar do jogo diversos exemplos de todas as formas de relevo e todos os processos erosivos, contudo foram selecionados apenas alguns para que a demonstração fosse possível. 
Figura 6 - Erosão antrópica (à esquerda) e planície de inundação (à direita)

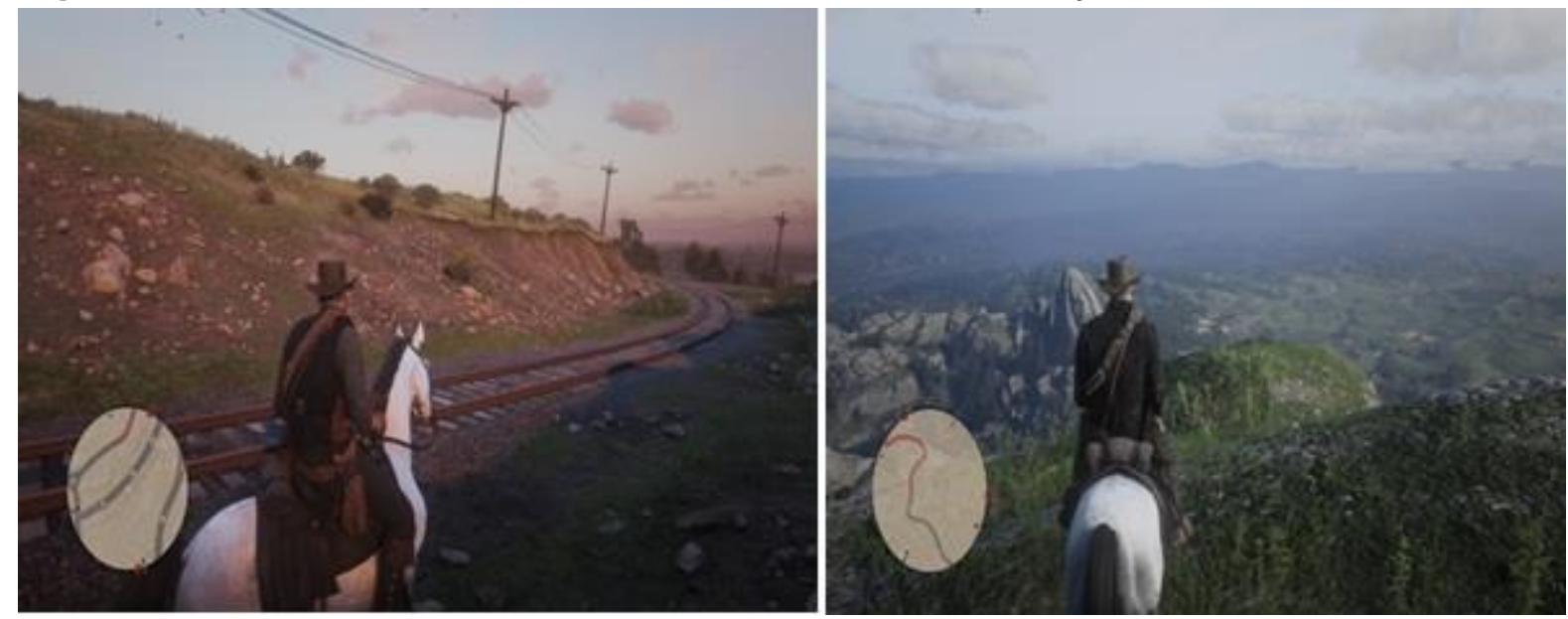

Fonte: Acervo particular dos autores, 2020 - Red Dead Redemption 2.

Geoformas: Nesta categoria foram selecionadas algumas geoformas de interesse geral, sem terem sido necessariamente nomeadas. Essas formas podem ser debatidas em sala de aula com os alunos e a partir delas o professor pode discutir suas nomenclaturas e características, bem como levantar problemáticas de como, por exemplo, o interesse cênico de tais formas poderia ser comparado a exemplos reais e se eles poderiam constituir interesse turístico a ponto de implantar, por exemplo, um geoparque no local.

Na figura 7 (à esquerda) podemos ver um exemplo de um dique de diabásio na rocha, ao se aproximar com o personagem é possível ver mais detalhadamente esta feição. $\mathrm{Na}$ direita da imagem há uma falha de rasgamento e ao se aproximar é possível observar as sigmoides.

Figura 7 - Diáclase dique de diabásio (à esquerda) e falha de rasgamento (à direita)

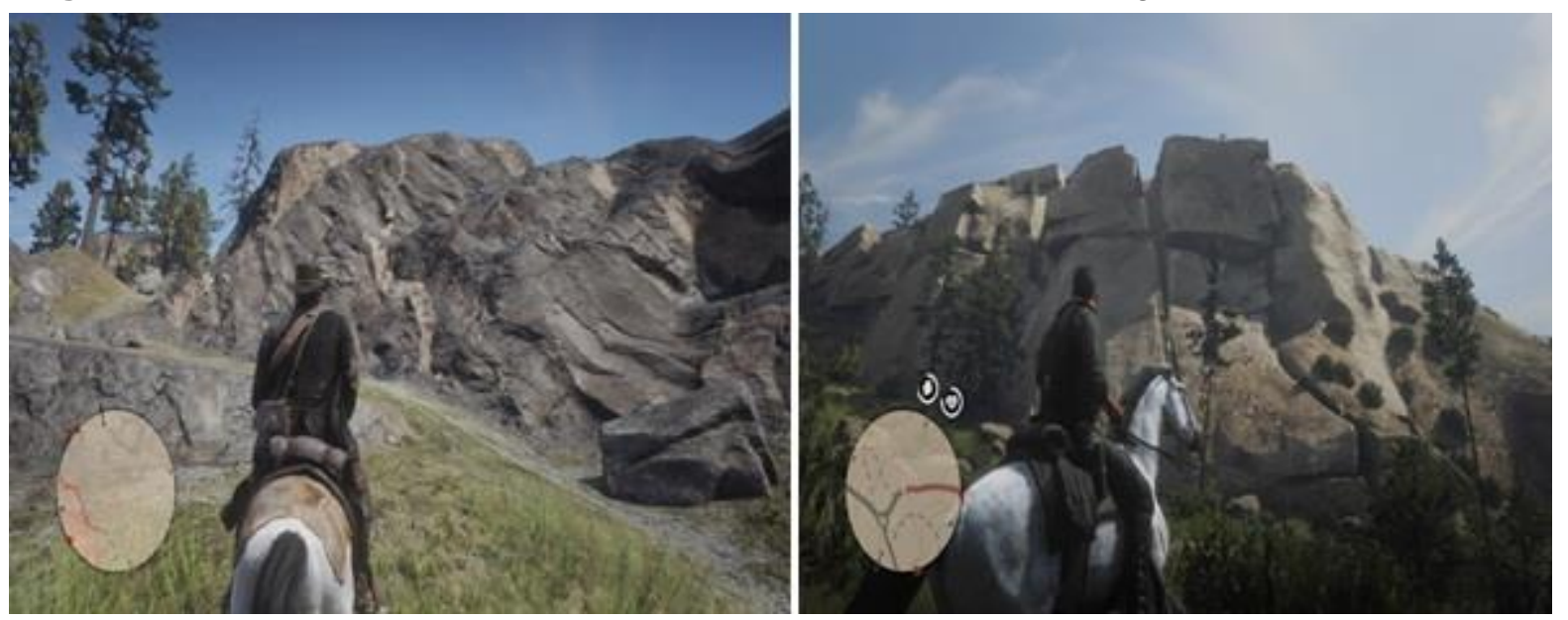

Fonte: Acervo particular dos autores, 2020 - Red Dead Redemption 2.

Paleoformas: O termo paleoformas não é aqui utilizado estritamente com o mesmo significado da Geomorfologia. Aliás, foi feito uso desse termo de maneira mais generalista, 
tendo em vista sua aplicabilidade. Assim, como paleoformas, considera-se aqui as imagens que tenham relação com o radical paleo, ou seja, paleontológico, paleolítico etc. Como exemplos apresenta-se algumas imagens de fósseis encontrados nas rochas e no solo e pinturas rupestres.

Nas representações da Figura 8 observa-se exemplos de fósseis de dinossauros, assim denominados no jogo, estando eles descobertos no solo ou nas rochas. Já na Figura 9 são exibidas pinturas rupestres, as primeiras descobertas dentro de uma caverna e as outras expostas em um rochedo ao ar livre. As imagens dessas categorias permitem não somente uma análise da geologia ou geomorfologia dos locais, mas também a construção de temáticas antrópicas, relativas ao uso que os humanos primitivos fizeram das rochas e do solo bem como problemáticas relativas à conservação e estudo desses sítios de interesse histórico e turístico.

Figura 8 - Exemplos de fósseis distribuídos pelo jogo

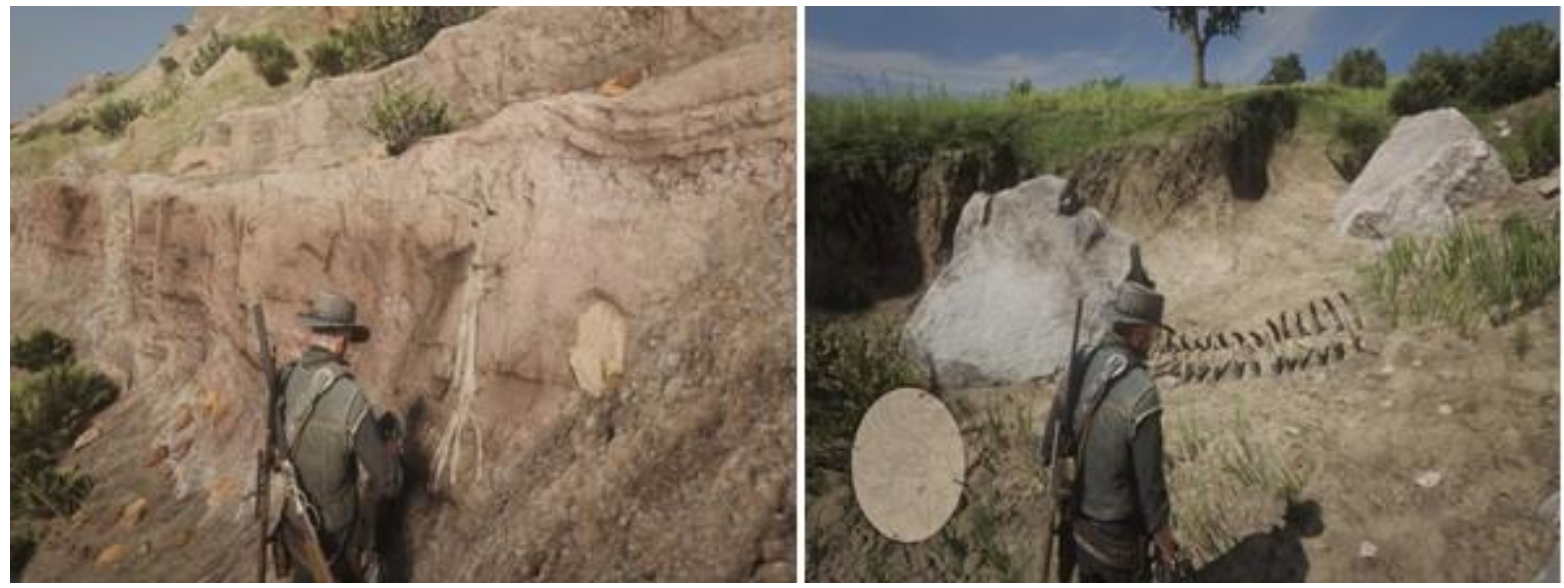

Fonte: Acervo particular dos autores, 2020 - Red Dead Redemption 2.

Figura 9 - Exemplos de pinturas rupestres
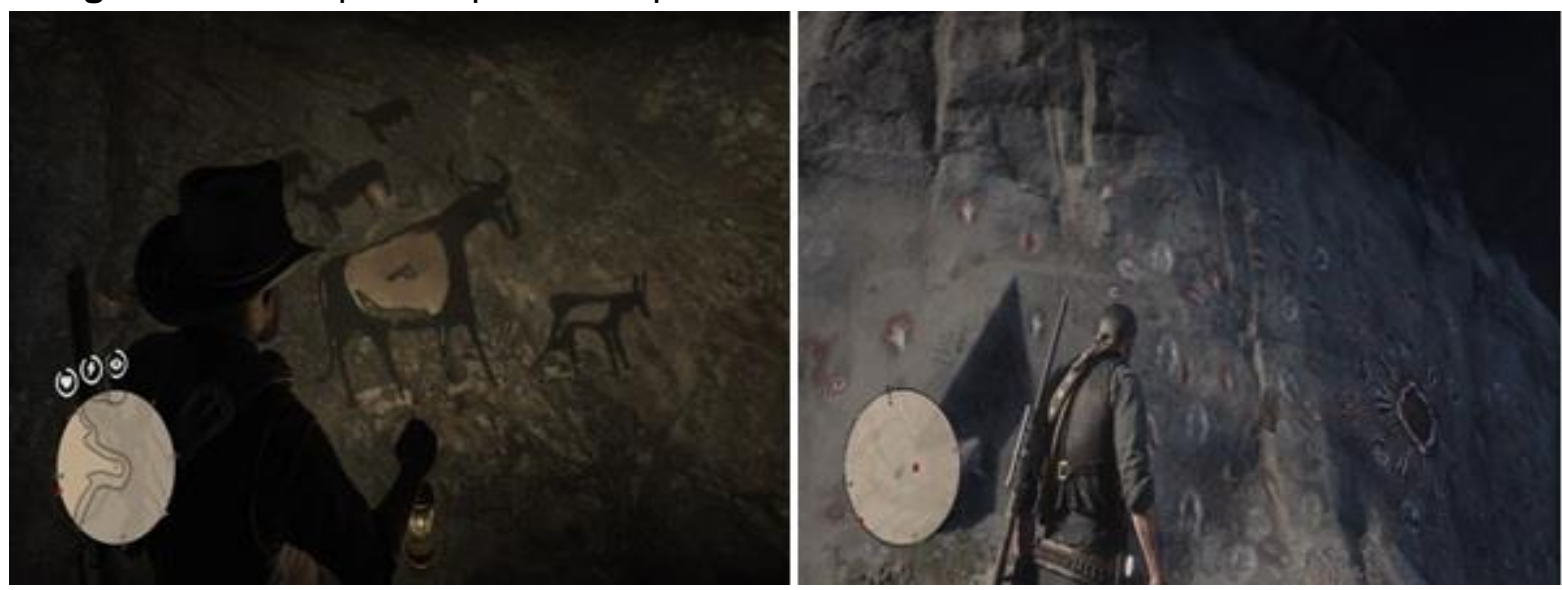

Fonte: Acervo particular dos autores, 2020 - Red Dead Redemption 2. 
Rochas em geral: Nesta categoria foram elencadas algumas entre diversas imagens de formações rochosas que podem ser utilizadas no ensino das geociências. Não são específicas de nenhum conteúdo, mas podem ser aplicadas conforme o direcionamento que queira ser dado às aulas. Nas imagens dessa seção os nomes já são auto-explicativos. Na Figura 10 (à esquerda) é possível observar algumas estrias glaciais, formadas pelo movimento de enormes geleiras durante a glaciação Permo-Carbonífera, parecidas com as que existem na colônia Witmarsum, no estado do Paraná. Na figura 10 à direita observa-se um grande bloco de basalto, ideal para explicar a origem das rochas que formam a grande maioria das ruas de paralelepípedo do Paraná.

Figura 10 - Estrias glaciais (à esquerda) e basalto (à direita)
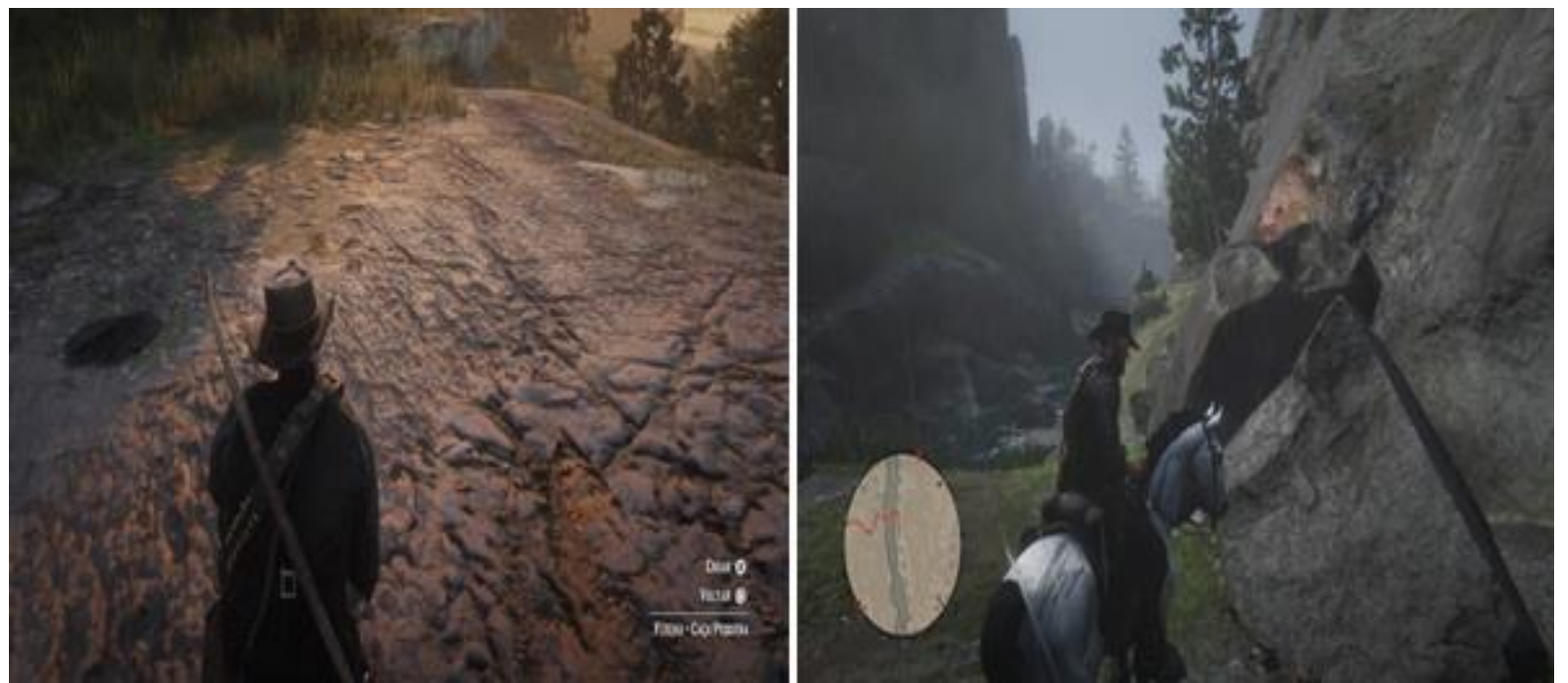

Fonte: Acervo particular dos autores, 2020 - Red Dead Redemption 2.

A partir dos resultados expostos, assevera-se que os docentes de Geografia possuem condições de usar esse jogo como aporte pedagógico, pondendo considerar para tal pratica: a) definição do tema que quer desenvolver; b) recorte de conteúdo teórico ao qual irá inserir o jogo como possibilidade pedagógica; c) conceitos centrais que podem ser abordados a partir da análise das paisagens expostas no jogo; d) objetivo de sua aula; e) como utilizará essa estratégia para ensinar; f) como avaliar o conhecimento do aluno ao interagir com o jogo. Estes aspectos, além de contemplar o jogo em si, trazem algumas possibilidades mais efetivas para o ensino escolar, trazendo uma aproximação maior entre os videogames e a aprendizagem significativa de conteúdos e conceitos da Geografia.

\section{CONSIDERAÇÕES FINAIS}

Os Gamestudies têm se consolidado como campo de pesquisa de diversas ciências, constituindo inclusive um campo epistemológico e metodológico próprio. As possibilidades de 
aplicação dos jogos e seus diversos mundos ditos virtuais são cada vez maiores, dada a intrínseca busca histórica e filosófica do sentido da realidade.

Para a área educacional, os jogos manifestam-se como ferramentas com utilidade empírica, pois podem atuar diretamente no processo de ensino e aprendizado. Ao fazer uso deles, os professores não apenas lançam mão de um instrumento de ensino lúdico, mas adentram uma nova perspectiva de cunho cultural-filosófico do qual as novas gerações estão cada vez mais inseridas, o chamado 'mundo digital', ou no caso dos gamestudies, os diversos mundos digitais existentes, repletos de possibilidades e representações tão reais que chegam a coexistir com o que se considera real.

No caso específico deste trabalho, não foram discutidos os conceitos filosóficos aplicados ao conceito de realidade dentro dos jogos, mas sim feito uso do jogo como uma ferramenta pedagógica com um objetivo específico, ou seja, o ensino de alguns conceitos da Geografia e Geologia. Ao percorrer o mundo de RDR2 foi possível localizar aspectos inerentes à temática ensinada como a cartografia, que permitiu o ensino da leitura dinâmica dos mapas, bem como geoformações de contexto gerais as quais poderiam ser impossíveis de se observar in situ em muitas situações, como por exemplo o processo erosivo causado pelo rio Colorado nos EUA, neste caso, do rio Bravo. Muito embora seja possível fazer uso de recursos como a internet ou filmes para apresentar tais formas aos alunos, eles não apresentam a mesma ludicidade e, mais especificamente, não apresentam a possibilidade de interação que o jogo produz, ou seja, o aluno pode literalmente percorrer os locais com o personagem e interagir de diversas maneiras com os sítios.

As possibilidades de utilização dos jogos como ferramenta pedagógica são inúmeras e, mesmo no caso desse estudo poderia-se destacar outras possibilidades que avançariam em pesquisas futuras, como por exemplo, a partir de um grupo de pesquisa, fazer um mapeamento completo do mundo do jogo, classificar todo o relevo, as regiões geológicas, a geomorfologia, os biomas etc. Essa prática, embora possa parecer irrelevante por se tratar de um mundo digital, é deveras pertinente, pois demanda conhecimentos específicos de geografia, geologia, geomorfologia e cartografia, e pode ser um instrumento de prática para os alunos dessas disciplinas que, ao trabalhar em sua elaboração, estariam colocando em prática o que lhes é ensinado nas aulas. Além disso, após terminados, os mapas poderiam ser utilizados no ensino dessas temáticas, ainda com o diferencial da ludicidade. Tal tarefa comparar-se-ia ao mapeamento de um estado, dada a complexidade da tarefa.

Finaliza-se assim esta abordagem dos gamestudies, um exemplo teórico-prático das possiblidades investigativas e educativas desse campo de pesquisa emergente e ainda pouco estudado, principalmente no Brasil. O desenvolvimento de novas pesquisas vem consolidado os jogos e seus mundos, sua influência na realidade em todos os aspectos, em uma área multidisciplinar da qual não é viável retirar o foco, dada a imersão cada vez maior das novas 
gerações nesses mundos e a necessidade cada vez mais latente que o mundo tem de novas tecnologias digitais. Assim, os liceus de aprendizagem e os métodos de ensino como um todo, com risco cair na obsolescência, devem inovar e caminhar junto às tendências cada vez mais digitais da humanidade.

\section{REFERÊNCIAS}

ALVARENGA, A. Grand Theft Auto: representação, espacialidade e discurso espacial em um videogame. 2007. Dissertação (Mestrado em Geografia) - Universidade Federal do Rio de Janeiro, Rio de Janeiro, 2007.

$\mathrm{ASH}, \mathrm{J}$. Emerging spatialities of the screen: video games and the reconfiguration of spatial awareness. Environment and Planning A, London, GB, v. 41, n. 9, p. 2105-2124, 2009.

BOELLSTORFF, T. Coming of age in second life: an anthropologist explores the virtually human. Princeton, NJ: Princeton University, 2010.

BOGOST, I. Unit operations: an approach to video game criticism. Cambridge: MIT, 2006.

CASTELLS, M. A sociedade em rede. São Paulo: Paz e Terra, 1999.

CLAVAL, P. As abordagens da geografia cultural. In: CASTRO, I.; GOMES, P.; CORREA, R. (org.) Explorações geográficas: percursos no fim do século. São Paulo: Bertrand Brasil, 1997. p. 89-117.

DODGE, M. Mapping cyberspace. London: Routledge, 2009.

DRUMMOND, W. Representação espacial nos videogames: explorando o caso Simcity 4. 2014. Dissertação (Mestrado em Geografia) - Universidade Federal do Rio de Janeiro, Rio de Janeiro, 2014.

HARDWICK, S. W. O ensino da geografia nos Estados Unidos. In: VESENTINI, J. W. (org.). O ensino de geografia no século XXI. Campinas: Papirus, 2004. p. 13-48.

HIGGIN, T. Blackless fantasy: the disappearance of race in massively multiplayer online roleplaying games. Games and Culture, Thousand Oaks, CA, v. 4, n. 1, p. 3-26, 2008.

JUUL, J. The open and the closed: game of emergence and games of progression. Tampere: Tampere University, 2002.

KAERCHER, N. A. O gato comeu a geografia crítica? Alguns obstáculos a superar no ensino aprendizagem de geografia. In: PONTUSCHKA, N. N.; OLIVEIRA, A. U. Geografia em perspectiva: ensino e pesquisa. São Paulo: Contexto, 2015. p. 45-65.

LACOSTE, I. A geografia: isso serve, em primeiro lugar, para fazer a guerra. Campinas: Papirus, 1988.

LEONARD, D. Young, black (\& brown) and don't give a fuck: virtual gangstas in the era of state violence. Cultural Studies Critical Methodologies, lowa City, v. 9, n. 2, p. 248-272, 2009.

LONGAN, M. Playing with landscape: social process and spatial form in video games.

Aether: The Journal of Media Geography, Los Angele, CA, v. 11, p. 23-40, 2008.

LOWOOD, H. Game studies now, history of science then. Games and Culture, Thousand Oaks, CA, v. 1, n. 1, p. 78- 82, 2006.

LÜDKE, M. A. Pesquisa em educação: abordagens qualitativas. São Paulo: EPU, 1986.

PINTO, F. R.; CARNEIRO, R. N. O ensino da geografia no século XXI: práticas e desafios do/no ensino médio. Revista Geolnterações, Assu, RN, v. 3, n. 2, p. 3-22, jul. /dez. 2019. 
POWER, M. Digitized virtuosity: video war games and post-9 / 11 cyber-deterrence. Security Dialogue, London, UK, v. 38, p. 271-288, 2007.

REEVES, S. Experts at play: understanding skilled expertise. Games and Culture, Thousand Oaks, CA, v. 4, n. 3, p. 205-227, 2009.

RELPH, E. Place and placeness. London: Pion, 1976.

SENE, J. E. A educação e o ensino de geografia: na era da informação ou do conhecimento? Revista Olhar de Professor, Ponta Grossa, PR, v. 13, n. 2, p.13-36, 2010.

SHAW, A. Putting the gay in games: cultural production and GLBT content in video games. Games and Culture, Thousand Oaks, CA, v. 4, p. 228-253, 2009.

SILVERSTONE, R.; HIRSCH, E. (ed.). Consuming technologies: media and information in domestic spaces. London: Routledge, 1992.

TUAN, Y.-F. Espaço e lugar: a perspectiva da experiência. São Paulo, DIFEL, 1983.

WITHEFORD, N. D.; PEUTER, G. D. Games of empire: global capitalism and videogames. Minnesota: University of Minnesota, 2009. 